\title{
Recovery from anterograde and retrograde amnesia after percutaneous drainage of a cystic craniopharyngioma
}

\author{
R. J. IGNELZI AND L. R. SQUIRE \\ From the Sections of Neurosurgery and Psychology, Veterans Administration Hospital, San Diego, and \\ Departments of Surgery and Psychiatry, University of California at San Diego, School of Medicine, La Jolla, \\ California, USA
}

SYNOPSIS A case is reported of a cystic craniopharyngioma involving the floor and walls of the third ventricle. Pronounced anterograde and retrograde amnesia were documented preoperatively by formal testing. Rapid improvement in both new learning capacity and remote memory occurred after percutaneous twist drill drainage of the cystic portion of the tumour. The relevance of these observations to the amnesic syndrome and its neuropathological basis is discussed.

Tumours involving the floor and walls of the third ventricle are frequently associated with memory impairment (Williams and Pennybacker, 1954; White and Cobb, 1955; Russell and Pennybacker, 1961; Kahn and Crosby, 1972; McEntee, Biber, Perl, and Benson, 1976). Although formal testing has rarely been conducted, there have been anecdotal reports of improved memory capacity after surgery in some of these cases. This case report describes the anterograde and retrograde amnesia associated with a cystic craniopharyngioma involving the floor and walls of the third ventricle, and provides objective evidence for global improvement of memory functions after percutaneous aspiration of the cyst.

\section{CASE REPORT}

The patient was a 51 year old, righthanded project engineer who was well until nine months before admission, when memory difficulties were noted by his family. The memory disturbances became progressively more severe, and three months later the patient had to stop working because of them. At the time of admission the patient was lethargic and hypersomnolent. When awakened he was cooperative but denied any memory difficulty. He knew that he was in a hospital but did not know why and could not remember the names of the physicians who attended

(Accepted 20 August 1976.) him. He had polydypsia and polyuria. There was loss of libido, and his skin was dry and pale. Cranial nerves were intact bilaterally except for a bitemporal visual field deficit. The remainder of the neurological examination was within normal limits.

A lumbar puncture revealed a normal opening pressure, with a protein concentration of $1.5 \mathrm{~g} / \mathrm{l}$. Cytology was negative. A brain scan was normal. Carotid angiography showed moderate dilatation of the ventricles and possible elevation of the A-1 segments of the anterior cerebral arteries. Vertebral angiography revealed stretching of the thalamorerforate arteries while the posterior cerebral arteries were displaced downward and posteriorly, suggesting a third ventricular mass. A pneumoencephalogram revealed a mass in the suprasellar area extending into the third ventricle. There was minimal hydrocephalus and the opening pressure was normal. The patient underwent a transventricular twist drill biopsy of the third ventricular mass under local anaesthesia, and $20 \mathrm{ml}$ of xanthochromic fluid was aspirated (Fig. 1). Electron microscopic examination of the fluid indicated cholesterol-laden macrophages suggestive of a craniopharyngioma. Despite the patient's dramatic improvement in memory function and his greater wakefulness after cyst aspiration, the bitemporal field deficit persisted as well as the polyuria and polydypsia. A subfrontal craniotomy was performed one week later, in an effort to decompress the optic chiasm, and subtotal removal of the tumour was accomplished. Pathological review of the tumour 


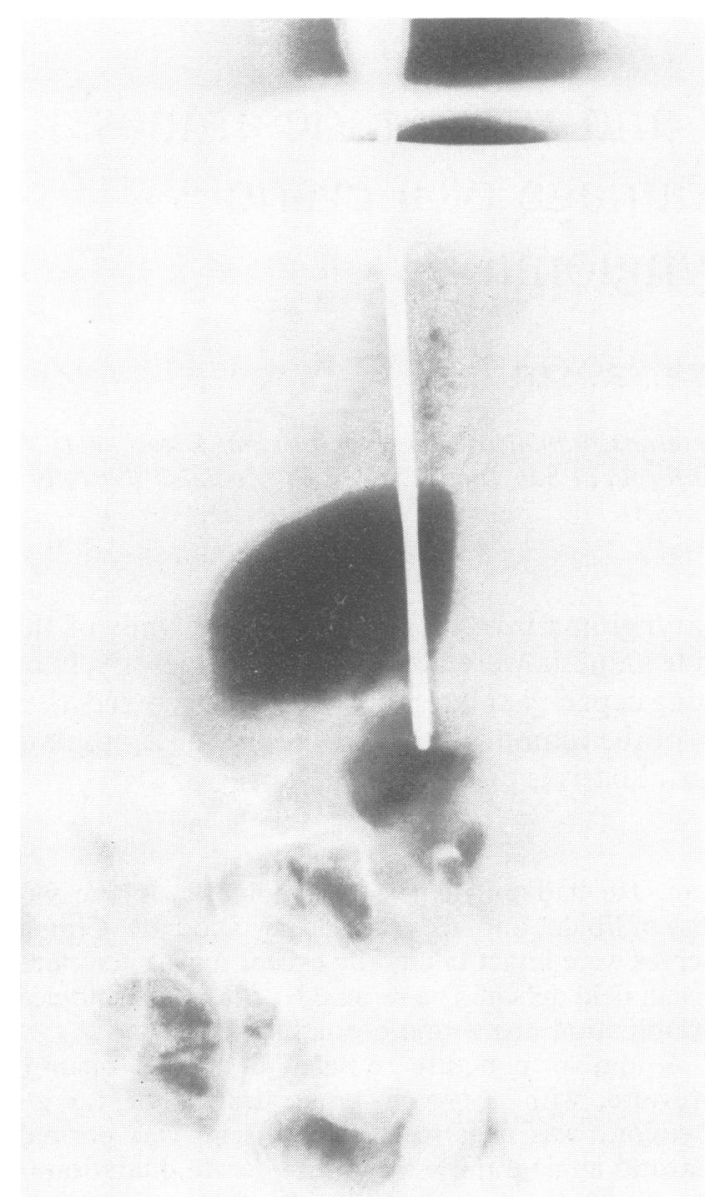

FIG. 1 Lateral intraoperative radiograph taken after drainage of the third ventricular cyst and instillation of air. The extent and location of the cystic portion of the tumour in the region of the third ventricle is well visualised.

specimen confirmed the diagnosis of a craniopharyngioma. Postoperative angiography indicated that the thalamoperforate and posterior cerebral arteries had returned to their normal positions.

During the patient's convalescence he suffered a massive pulmonary embolus and died. Postmortem examination revealed the immediate cause of death to be the pulmonary embolus. The remaining tumour was adjacent to the mammillary bodies, and the decompressed cyst lined the walls and floor of the third ventricle. Microscopic review of the diencephalon revealed a diffuse subependymal gliosis with intact thalamic nuclei bilaterally. The remainder of the diencephalon exhibited no abnormalities that could be attributed to the cyst or tumour.

\section{MEMORY TESTS}

Before and after surgery, three tests of new learning capacity and remote memory were administered. Tests 1 and 2 have been described in detail previously (Squire and Chace, 1975). Test 1 consisted of 32 items, eight in each of the following four categories: pictures of common objects, photographs of faces, nonsense line drawings, and common words. For learning, each item was presented for three seconds. Immediately afterwards, retention was tested by presenting 32 sets of three items. Each set of three included one item just seen and two new (incorrect) items. For each set of three, the subject was asked to point to the item he had seen before. Delayed retention was tested 24 hours later by asking the subject once again to select the items he had seen before. Different incorrect items were used for the immediate an $\Phi$ delayed retention tests. Equivalent forms of this tes were administered on two occasions: before surgery and three days after cyst evacuation.

Test 2 involved the reproduction of a comple geometric figure from memory. The subject was askeक 의 to copy the Rey-Osterrieth figure (Osterrieth, 1944\% taking care to include all line segments. One day later without forewarning, the subject was asked to reproo duce this figure from memory. The score on this tese was the number of properly positioned line segments and the maximum score was 42 points.

Test 3 was based on previously described remote memory tests (Warrington and Sanders, 1971; Squire, 1974) and asked for recall of information about events that had occurred from 1950 to 1959. The test consisted of 23 questions about wellpublicised names and events of that decade (example: what was the Andrea Doria?), and the score on this test was the number of questions answered correctly. This test was administered before surgery and again three days after surgery.

\section{Before aspiration of cyst}

On the Wechsler Adult Intelligence Scale the patient scored in the bright-normal range (117). Digit span was eight forward and seven backward. The results for Test 1 are shown in Fig. 2. Immediately after learning, 27 of the 32 items were recognised correctly. After a delay of 24 hours, only 18 items were recognised, and this score was well below the lowest score (24) obtained by a group of control subjects of similar age (mean $=45$ years) and educational background (mean $=12$ years). The impairment was pronounced for both verbal and nonverbal items. 


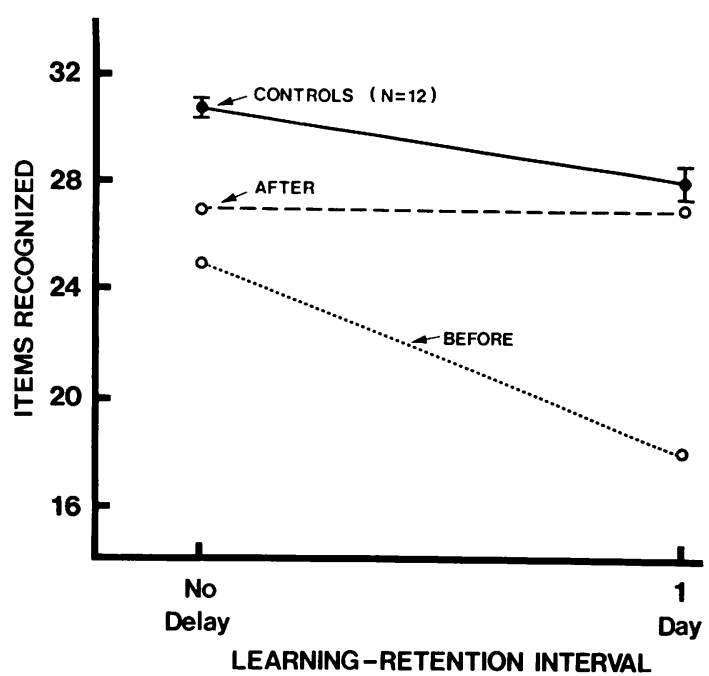

FIG. 2 Score on a 32 item recognition memory test administered three weeks before and three days after cyst aspiration. A control group of comparable age and educational background was also tested.

The patient copied the geometric figure accurately (Test 2), but 24 hours later could not reproduce any part of it, and denied having seen a figure on the previous day. The mean score for control subjects on this test was 15.9.

Results for the remote memory test are shown in the Table. The score of eight correct out of 23 was outside the range of scores obtained by the control subjects.

T A B L E

RECALL FROM REMOTE MEMORY

\begin{tabular}{lllr}
\hline & $\begin{array}{l}\text { Information } \\
\text { subtest }\end{array}$ & $\begin{array}{l}\text { Remote memory score } \\
(1950-59)\end{array}$ \\
\hline Patient & 20 & Before surgery r & 8 \\
Controls $(\mathrm{N}=8)$ & $20.8 \cdot t 1.1$ & After surgery 14 \\
\hline
\end{tabular}

The patient took the remote memory test and the information suttest of the Wechsler Adult Intelligence Scale. Memory testing occurred three weeks before and three days after surgery. Control scores are means $t$ standard errors.

\section{After aspiration of cyst}

Figure 2 indicates that after cyst aspiration considerable improvement occurred in the ability to retain newly learned material (Test 1 ). Delayed recognition memory was within the normal range, although still below the mean score obtained by the control group On Test 2, the patient obtained a score of 13, which placed him in the lower third of the normal range. The Table shows that after cyst aspiration considerable improvement also occurred in remote memory capacity (Test 3 ). The score at this time was 14 , just below the mean score obtained by the control subjects.

\section{DISCUSSION}

The role of midline diencephalic structures in the amnesic syndrome has been well documented. Patients with the Korsakoff syndrome exhibit anterograde amnesia and a variable period of retrograde amnesia in the absence of disturbances of immediate memory or intellectual capacity (Talland, 1965). The loss of remote memory can extend to material acquired many years before the onset of illness (Talland, 1965; Sanders and Warrington, 1971; Seltzer and Benson, 1974). This amnesic syndrome appears to be associated with lesions in the dorsomedial thalamus, mammillary bodies, and in the terminal aspects of the fornix (Brierly, 1966; Victor et al., 1971), but there is disagreement as to what constitutes the minimal lesion in these regions. The integrity of the mammillary bodies has traditionally been considered to be required for normal memory function (Brierly, 1966). However, a few cases have been reported in which lesions confined to these nuclei were not associated with amnesia (Victor et al., 1971). In summary, it has not yet been possible to correlate the severity of anterograde amnesia or the length of retrograde amnesia to lesions in any of these regions, and it remains possible that damage in other areas of the diencephalon may sometimes contribute to the psychological deficit.

Memory disturbances can also result from tumours that invade the floor and walls of the third ventricle (Williams and Pennybacker, 1954; White and Cobb, 1955; Russell and Pennybacker, 1961; Kahn and Crosby, 1972; McEntee et al., 1976). In these cases, loss of recent and remote memory can be accompanied by drowsiness or confusion, and all these symptoms can be diminished by surgery according to these authors. In the absence of formal psychological testing, however, it has not been completely clear to what extent remote memory was affected, or recovery occuried.

The case described here is unique in that the results of psychological testing are available before and after drainage of a partially cystic craniopharyngioma. Before surgery, the patient exhibited an aboveaverage immediate memory and intellectual capacity, together with profound anterograde and retrograde 
amnesia. The retrograde amnesia affected memories acquired as long as 20 years before the onset of illness. The memory impairment, including the prolonged retrograde amnesia, closely resembled the amnesic syndrome previously reported to result from Korsakoff's psychosis (Talland, 1965; Sanders and Warrington, 1971; Seltzer and Benson, 1974), electroconvulsive therapy (Williams, 1966; Squire, 1975), or from severe head injury (Russell and Nathan, 1946; Benson and Geschwind, 1967). After surgery, anterograde amnesia was markedly reduced, and remote memory capacity improved to near normal levels.

This case demonstrates several important points about the amnesic syndrome. The exact site of the neuroanatomical changes underlying this amnesic syndrome cannot be established with certainty. Since there were no neuropathological changes in the diencephalon that could be attributed to the tumour, it seems reasonable to suppose that percutaneous drainage of the cyst resulted in reduction of pressure, and that this reduction of pressure was responsible for recovery of memory functions. The cyst was located in the floor and walls of the third ventricle and presumably exerted pressure on the thalamus. The solid portion of the tumour was found ventral to the cyst and adjacent to the mammillary bodies. Although it seems likely that the amnesia may have resulted primarily from compression of structures contiguous to the third ventricle, the possibility that the effects of the cyst may have involved other areas, including the mammillary bodies, cannot be ruled out.

The present case is the first in which it has been possible to document dramatic and rapid improvement in remote memory after surgery. A parallel improvement in new learning capacity and remote memory has been noted previously during recovery from severe head trauma (Russell and Nathan, 1964; Benson and Geschwind, 1967), but little is known about the brain regions participating in this improvement. The present case suggests that both remote memory capacity and new learning capacity can depend to some extent on the integrity of a common anatomical substrate in a relatively circumscribed brain region, since remote memory and new learning were both rapidly improved by a specific drainage procedure in the region of the third ventricle. The fact that remote memory recovered indicates clearly that a remote memory defect can involve a temporary loss of accessibility to memory, rather than erasure of memory. This point has been noted previously for loss of remote memory caused by head trauma (Russell and Nathan, 1946; Benson and Geschwind, 1967) or electroconvulsive therapy (Squire et al., 1975).
Whereas severe anterograde amnesia and a remote memory defect were associated in the present case, severe amnesia is not always associated with a defect in remote memory. The patient H.M. with bilateral medial temporal lesions (Milner, 1972) and the patient N.A. with a midline stab wound (Teuber et al., 1968), have exhibited dense anterograde amnesia since the onset of their amnesic syndromes in 1953 and 1960, respectively, yet both these individuals exhibit a normal ability to recall events that occurred up to about a year before the onset of amnesia (Marslen-Wilson and Teuber, 1975; Squire and Slater, to be published). It seems possible that the absence of remote memory defects in these two cases might be related to the purity of their amnesic syndromes. H.M. and N.A. are alert and exhibit no known cognitive defect other than severe amnesia (Teuber et al., 1968; Milner, 1972). By contrast, the remote memory defect exhibited in the present case occurred in association with hypersomnolence, loss of initiative, and denial of illness. Patients with Korsakoff's syndrome also exhibit lethargy, loss of initiative, and other cognitive dysfunction (Talland $\frac{p_{p}}{\vec{N}}$ 1965).

The present case of third ventricular tumour add to the list of conditions where the existence of remote memory defect has been documented with objective tests. Remote memory defects seem to occur with acute amnesia as caused by electro 0 convulsive therapy (Squire, 1975) or unusuall $\overparen{\Phi}$ ) severe head trauma (Russell and Nathan, 1946); of 궁 with severe chronic conditions like Korsakof psychosis (Sanders and Warrington, 1971; Seltze $\overrightarrow{+}$ and Benson, 1974) and craniopharyngioma that involve widespread dysfunction in the diencephalic midline, and that are associated with some cognitive dysfunction in addition to amnesia.

We thank Dr Peter Lampert for his neuropathological evaluation, and Pamela Slater for assistance with testing. This work was supported by research grants 0323-01 and 4049-01 from the Veterans Administration to Dr Ignelzi; and by NIMH Grant MH24600 and by Clinical Investigatorship 8084-C from the Veterans Administration to Dr Squire.

\section{REFERENCES}

Benson, F., and Geschwind, N. (1967). Shrinking retrograde amnesia. Journal of Neurology, Neurosurgery, and Psychiatry, 30, 539-544.

Brierly, J. B. (1966). The neuropathy of amnesic states. In Amnesia, pp. 150-180. Edited by C. W. M. Whitty and O. L. Zangwill. Appleton-Century-Crofts: New York.

Kahn, E. A., and Crosby, E. C. (1972). Korsakoff's syndrome associated with surgical lesions involving the mammillary bodies. Neurology (Minneap.), 22, 117-125.

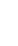


Marslen-Wilson, W. D., and Teuber, H.-L. (1975). Memory for remote events in anterograde amnesia: Recognition of public figures from newsphotographs. Neuropsychologia, 13, 353-364.

McEntee, W. J., Biber, M. P., Perl, D. P., and Benson, F. D. (1976). Diencephalic amnesia: a reappraisal. Journal of Neurology, Neurosurgery, and Psychiatry, 39, 436-441.

Milner, B. (1972). Disorders of learning and memory after temporal lobe lesions in man. Clinical Neurosurgery, 19, 421-446.

Osterrieth, P. (1944). Le test de copie d'une figure complexe. Archives of Psychology, 30, 206-356.

Russell, W. R., and Nathan, P. W. (1946). Traumatic amnesia. Brain, 69, 280-300.

Russell, W. R., and Pennybacker, J. B. (1961). Craniopharyngioma in the elderly. Journal of Neurology, Neurosurgery, and Psychiatry, 24, 1-13.

Sanders, H., and Warrington, E. K. (1971). Memory for remote events in amnesic patients. Brain, 94, 661-668.

Seltzer, B., and Benson, D. F. (1974). The temporal pattern of retrograde amnesia in Korsakoff's disease. Neurology (Minneap.), 24, 527-530.

Squire, L. R. (1974). Remote memory as affected by aging. Neuropsychologia, 12, 429-435.

Squire, L. R. (1975). A stable impairment in remote memory following electroconvulsive therapy. Neuropsychologia, 13, 51-57.
Squire, L. R., and Chace, P. M. (1975). Memory functions six to nine months after electroconvulsive therapy. Archives of General Psychiatry, 32, 1557-1564.

Squire, L. R., Slater, P. C., and Chace, P. M. (1975). Retrograde amnesia: temporal gradient in very long term memory following electroconvulsive therapy. Science, 187, 77-79.

Talland, G. A. (1965). Deranged Memory, p. 356. Academic Press: New York.

Teuber, H.-L., Milner, B., and Vaughan, H. G. (1968). Persistent anterograde amnesia after stab wound of the basal brain. Neuropsychologia, 6, 267-282.

Victor, M., Adams, R. D., and Collins, G. H. (1971). The Wernicke-Korsakoff Syndrome, p. 206. Davis: Philadelphia.

Warrington, E. K., and Sanders, H. (1971). The fate of old memories. Quarterly Journal of Experimental Psychology, 23, 432-442.

White, J. C., and Cobb, S. (1955). Psychological changes associated with giant pituitary neoplasms. Archives of Neurology and Psychiatry (Chic.), 74, 383-396.

Williams, M. (1966). Memory disorders associated with electroconvulsive therapy. In Amnesia, pp. 134-149. Edited by C. W. M. Whitty and O. L. Zangwill. Appleton-Century-Crofts: New York.

Williams, M., and Pennybacker, J. (1954). Memory disturbances in third ventricle tumours. Journal of Neurology, Neurosurgery, and Psychiatry, 17, 115-123. 